\title{
Attenuation of passive avoidance by continuous septal stimulation'
}

Phyllis Kasper MCGILL UNIVERSITY

\begin{abstract}
Abstraet
Water deprived rats receiving mild, continuous electrical stimulation of the septal area accept more mouth shocks in a water-shock conflict situation, and defecate and freeze less than control subjects. The effect on number of shocks accepted is greater for lateral than for medial septal stimulation.
\end{abstract}

\section{Problem}

It has been shown that rats with lesions in the septal area of the brain have difficulty in acquiring the passive avoidance response in a water-shock conflict situation (Kaada et al., 1962). This study tests the prediction that rats receiving mild, continuous septal stimulation show a similar deficiency in the development of passive avoidance.

\section{Subjects}

Thirty-one male hooded rats were used. Twenty received brain stimulation (Group E), four served as fully operated controls, and seven as unoperated controls (collectively Group C).

\section{Procedure}

Subjects of Group E, and operated controls were implanted with bipolar silver electrodes aimed at either the lateral or medial septal nucleus. Two to three weeks were allowed for recovery, and all Ss were handled during this period.

All Ss spent four 20-min. sessions in the $9 \times 9 \times 12-$ in test chamber while under 23-hr. water deprivation. They were observed through a plastic window in one side of the chamber. Subjects of Group E received continuous electrical stimulation from a Grass S4 Stimulator in the form of $20 \mu \mathrm{A}, 100 \mathrm{cps}$ square waves $0.5 \mathrm{msec}$. in duration, throughout all four sessions. The first session was an adaptation period during which all Ss were allowed to drink freely from a metal water spout which projected from one wall of the chamber. On each of the three $20-\mathrm{min}$. test sessions Ss were allowed to drink for the first $5 \mathrm{~min}$., and then the spout was electrified for the remaining 15. The number of mouth shocks accepted by each rat, and the number of fecal boli dropped were counted. The amount of time spent frozen and the latency of the first daily contact with the spout were recorded by stopwatch for ten Group E Ss and four from Group C.

Following testing on passive avoidance, Group E animals were allowed free access to water for a week. They were then given an opportunity to press a bar for 0.5 sec. of brain stimulation at varying intensities. Thresholds were approximated by the method of limits, and all Ss were tested for responses to $20 \mu \mathrm{A}$.
Group E Ss were tested for heart rate changes in response to stimulation while unrestrained in an 8.5-in cubic box. Test stimuli were $0.5 \mathrm{sec}$. trains delivered over a $2-10 \mathrm{~V}$ range. Heart responses were recorded on a Grass Model 5 Polygraph.

\section{Results}

Group E accepted about twice as many mouth shocks in total as did Group C, p <.01, Mann-Whitney U test (see Fig. 1). Both experimental and control groups accepted fewer shocks as sessions progressed, $\mathrm{p}<.001$, Ferguson's nonparametric trend test (Ferguson, 1962).

Subjects with lateral septal electrodes accepted more mouth shocks than did those with other placements, $\mathrm{p}<.05$, Mann-Whitney U test. This localization of effect is indicated in Fig. 2.

Groups $\mathrm{E}$ and $\mathrm{C}$ showed opposite trends on amount of time spent frozen. Group E decreased time frozen and Group C increased time frozen over shock sessions one to three, $\mathrm{p}<.002$, Ferguson's nonparametric trend test. By the final session, the groups differ on this measure, $\mathrm{p}<.01$, Mann-Whitney U test. Freezing usually occurred between bursts of approach-withdrawal responses, with the rats remaining oriented toward the spout while

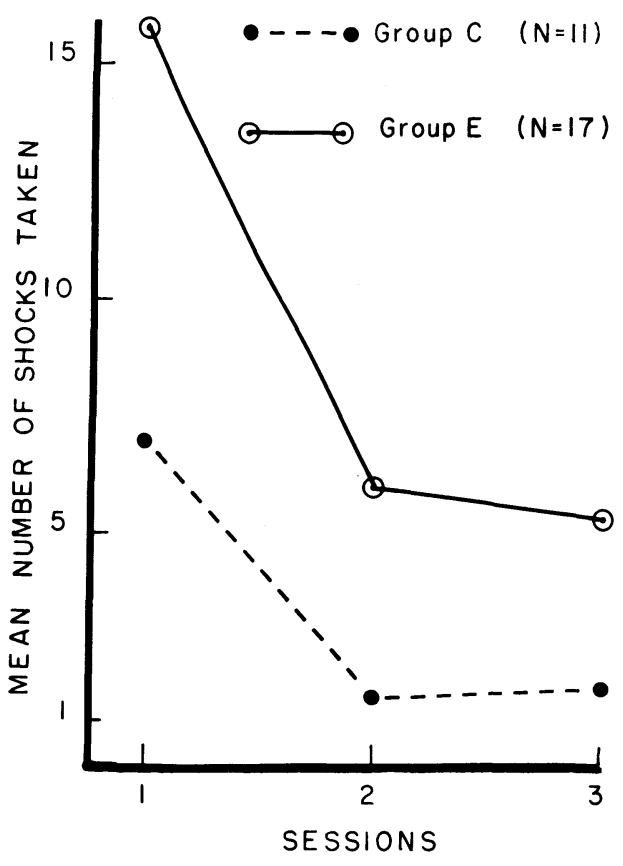

Fig. 1. Mean number of mouth shocks taken during daily sessions. 

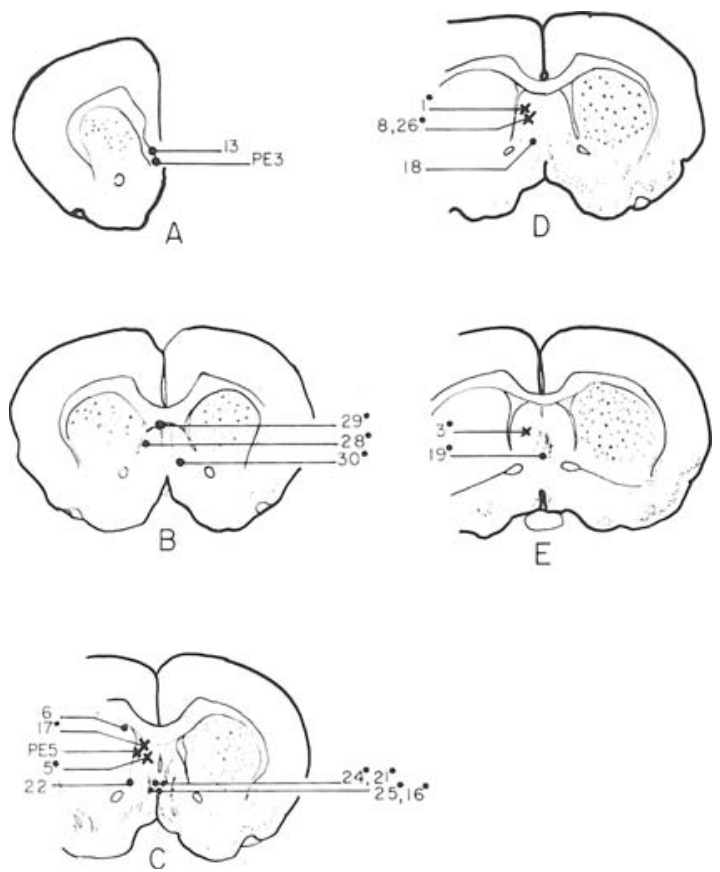

Fig. 2. Schematic representation of histological data on Group E. Crosses indicate the placements of Ss that accepted 20 or more mouth shocks on the first test session; dots indicate all other placements. Subjects marked with a dot to the upper right of their number would bar-press for stimulation.

frozen. As the sessions progressed, control Ss tended to make fewer approach-withdrawal responses, and began to crouch facing away from the spout.

Group C dropped more fecal boli than Group E on the adaptation session and on the three shock sessions, $\mathrm{p}<.01$ (sign-test) and $\mathrm{p}<.025$ (Mann-Whitney U test), respectively.

There were no differences in latency of approach to water as measured prior to the introduction of the mouth shock.

The Ss bar-pressing behavior appeared to be in no way related to their passive avoidance behavior (see Fig. 2). Only S 28 would press for $20 \mu \mathrm{A}$. The other Ss' thresholds ranged from 50-350 $\mu$ A, and bore no obvious relationship to the number of shocks accepted.

The heart rate change in response to stimulation depended upon the location of the electrode within the septal complex, the lateral placements yielding slowing, and medial placements yielding a brief initial speeding followed by slowing. Similar findings by different investigators have recently been reviewed by Malmo
(1964). Both the autonomic and behavioral data are thus in support of the notion of functional differentiation within the septal area.

Subjects often responded to the relatively high intensities of stimulation used during bar training and heart response testing by freezing during the stimulation and shaking and defecating afterward. At no time did they show such responses to the $20 \mu \mathrm{A}$.

\section{Diseussion}

That the experimental animals defecated and froze less than the controls suggests that they were less "distressed." This type of emotional hypothesis has been put forth by Brady \& Conrad (1960) to explain their finding that rats bar-pressing for septal stimulation do not show conditioned emotional responses.

An equally, or perhaps more plausable notion is that the continuous stimulation interferes with the normal functioning of a circuit controlling response inhibition. This type of explanation would permit an integration of data from stimulation and lesion studies. Septal lesioned Ss tend to be wild (Schwartzbaum \& Spieth, 1964), while the stimulated Ss are apparently calm and tame. Despite this difference in "emotionality," both lesioned and stimulated rats are impaired in the development of passive avoidance (Kaada et al., 1962; Schwartzbaum \& Spieth, 1964). Furthermore, the notion of disruption of a circuit serving response inhibition could encompass data on avoidance deficits following lesions of the frontal, and hippocampal areas, which are anatomically related to the septal area (Kimura, 1958; Maher et al., 1962).

\section{References}

BRADY, J. V., \& CONRAD, D. G. Some effects of limbic system selfstimulation upon conditioned emotional behavior. J.comp.physiol. Psychol., 1960, 53, 128-137.

FERGUSON, G. A. Nonparametric trend analysis. Unpublished manuscript, McGill University, 1962.

KAADA, B. R., RASMUSSEN, E. W., \& KVEIM, O. Impaired acquisition of passive avoidance by subcallosal, septal, hypothalamic, and insular lesions in the rat. J. comp. physiol. Psychol., 1962, 55, 661-670. KIMURA, DOUGLAS. Effects of selective hippocampal damage on avoidance behavior in the rat. Canad. J. Psychol., 1958, 12, 213-218. MAHER, B., ELDER, S. T., \& NOBLIN, C. D. A differential investigation of avoidance reduction versus hypermotility following frontal ablation. J.comp. physiol. Psychol., 1962, 55, 449-454.

MALMO, R. B. Heart rate reactions and locus of stimulation within the septal area of the rat. Science, 1964, 144, 1029-1030.

SCHWARTZBAUM, J. S., \& SPIETH, T. M. Analysis of the responseinhibition concept of septal functions in "passive-avoidance" behavior. Psychon. Sci., 1964, 1, 145-146.

\section{Note}

1. This research was supported in part by grants from the National and Medical Research Councils, and the Defence Research Board of Canada, and from the National Institutes of Health, United States Public Health Service. Portions of the work presented are included in a thesis submitted to the Graduate Faculty of McGill University in partial fulfillment of the requirements for the M.Sc. degree in psychology, and have been presented at the Eastern Psychological Association in Philadelphia in April 1964. 